\title{
The impact of a new light rail system on single-family property values in Charlotte, North Carolina
}

\author{
Sisi Yan \\ Environmental Systems Research \\ Institute (ESRI)
}

\author{
Eric Delmelle \\ The University of North Carolina ${ }^{a}$
}

\author{
Michael Duncan \\ Florida State University ${ }^{b}$
}

\begin{abstract}
This paper examines the impact of a new light rail system on single-family housing values in Charlotte, North Carolina, from 1997 to 2008 . We use a Hedonic Price Analysis (HPA) to estimate how proximity to light rail, housing characteristics, and spatial components (at a block group level) affect single-family housing values. The same method is applied to each of the four time periods ( $\mathrm{t} 1, \mathrm{t} 2$, $\mathrm{t} 3$, $\mathrm{t} 4$ ) that coincide with the pre-planning, planning, construction, and operation phase of the light rail system. We observe a trend that suggests a greater desirability to live closer to a light rail station as the transit system becomes operational.
\end{abstract}

\section{Introduction}

From the latter part of the $20^{\text {th }}$ century until today, city and regional planners have promoted reliable public transportation as a sustainable element of their transportation systems. This can be attributed to an increasing awareness of sustainability among planners and the general public. Although personal automobiles are convenient and provide travel flexibility, they also cause congestion and accidents, increase energy consumption and emissions, generate sprawl, and exclude low-income and disabled populations (Richardson 1999). To reduce personal reliance on the automobile and address the social and environmental issues mentioned above, most major European cities have invested in rail systems as an alternate mode of transportation. In the United States, cities such as Portland, Boston, and San Francisco have adopted light rail systems, which has influenced their morphology over time (Muller 1995). The benefits public transit offer are relatively inexpensive transportation and the flexibility for workers to reside in suburban areas instead of the center city. Finally, public transit raises transportation equity standards for people with limited access to private transportation (Dunbaugh 2008; Ong and Houstion 2002).

Transit impact studies are generally based on hypotheses that assert that improved accessibility will increase land value. Alonso (1964) suggested that locating closer to the central business district (CBD) reduces commuting costs at the expense of higher land rents. The underlying principle of Alonso's work broadly applies to any location with a high level of accessibility, such as areas near highway interchanges and rail stations. It is generally acknowledged that transportation investments such as corridor development will improve the value of land adjacent to these developments, since commuting time may be reduced. In addition, increasing accessibility will attract more activities and spatial interaction to these places (Gatzlaff and Smith 1993).

In this study, we are interested in evaluating whether individuals are willing to invest more money when purchasing a residential property located in proximity to a light rail station in Charlotte, North Carolina. What makes this study unique are the characteristics of the light rail line: (1) it is a short line; (2) it is located in a fairly low-density urban area; and (3) it uses the track of a former freight line. In addition, the light rail was conceived and built during a period of rapid urban expansion. Recent studies suggest that a rapid transit station is likely to affect the price of housing within a certain proximity, usually within 1600 meters (roughly one mile) of a station. (Gatzlaff 1993; Huang 1996; Ryan 1999). Many studies have found positive relationships between real estate values and proximity to fully developed light rail systems (Davis 1970; Lee 1973; Baldassare et al. 1979; Benjamin and Sirmins 1996; Lewis-Workman and Brod 1997; Weinstein and Clower 2002; Cervero and Duncan 2002). Conversely, no relationship was found between home prices and proximity to the semi-developed rail system of Miami (Gatzlaff and Smith 1993). For a detailed analysis of this literature, we refer the reader to a handful of papers that have been dedicated to reviewing research about the impacts of rail on real estate values: Bartholomew and Ewing (in press), Debrezion, Pels and Rietveld (2007), Ryan (1999), and Knight and Trigg (1977).

Most of the previous work in this area applies a cross-sectional approach. In other words, there is no temporal component to the analysis, and the implicit price of station proximity

a eric.delmelle@uncc.edu

b mdduncan@fsu.edu

Copyright 2012 Sisi Yan, Eric Delmelle and Michael Duncan.

Licensed under the Creative Commons Attribution - NonCommercial License 3.0. 
is determined by statistically controlling for all other factors (Rosen 1974). An alternate approach analyzes sales transactions before and after the introduction of the rail system (Damm et al. 1980; Dunphy 1982; Grass 1992; Voith 1993; McDonald and Osuji,; 1995; McMillen and McDonald 2004; Gibbons and Machin 2005; Agostini, C. and G. Palmucci 2008). This can presumably provide statistical evidence of causality that cannot be obtained by a cross-sectional study (Gibbons and Machin 2005). This analysis will adopt such a longitudinal approach. Previous longitudinal analyses (as cited above) often demonstrate that housing markets anticipate the opening of a light rail system as soon as the plan is revealed to the public. As such, we measure how Charlotte housing prices react to the different implementation phases of the light rail system: preplanning, planning, construction, and operation.

\section{Case study}

\subsection{Charlotte and the light rail blue line}

According to the Mecklenburg County Planning Commission, Charlotte jumped from the 47th to the 20th most populated city in the United States between 1980 and 2005. The Charlotte Metropolitan Statistical Area (MSA) ${ }^{1}$ had a population of $1,330,439$ in 2000 (US census) and an estimated population of 1,651,568 in 2007-a 3.45 percent growth rate. The population in the Charlotte MSA maintains a steady growth rate, higher than both North Carolina and the United States. Due to the development of the banking industry, Charlotte became a financial city, attracting businesses such as Bank of American, Duke Energy, Wachovia (now Wells Fargo), and USairways. Bank of America played a pivotal role in pushing for center city redevelopment, revitalization of the $\mathrm{CBD}$, and gentrification of the surrounding center city neighborhoods.

To control urban growth, the Mecklenburg Planning Commission made its first recommendation for a rapid transit system in southern Charlotte. The discussion for a possible light rail plan originated from the early successful trolley lines that had fostered the growth of neighborhoods such as Myers Park, Plaza-Midwood, Wilmore, and Dilworth rather than sprawling subdivisions (see Figure 1). In late 1998, Mecklenburg County voters approved a one-half-cent sales tax increase to be used toward the 2025 Integrated Transit/Land-Use Plan. This plan included the development of a light rail network, known as the blue line of the LYNX system. Official groundbreaking

1 The Charlotte Metropolitan Statistical Area (MSA), also referred to as the Charlotte-Gastonia-Concord MSA, covers the larger Charlotte metro region (Mecklenburg County) as well as four other counties in North Carolina and one in South Carolina. for the line eventually occurred on February 26, 2005, and the transportation system became operational on November 24, 2007 (Rapid Transit Planning 2010). The new light rail system is a $15.5-\mathrm{km}$ line, connecting the Charlotte CBD to the suburban area to the south of the city using a railroad right-of-way. The line has 15 stations, 5 of them located in the CBD area (Figure 1). Park-and-ride locations are available for 7 southernmost stations (those farthest from the CBD).

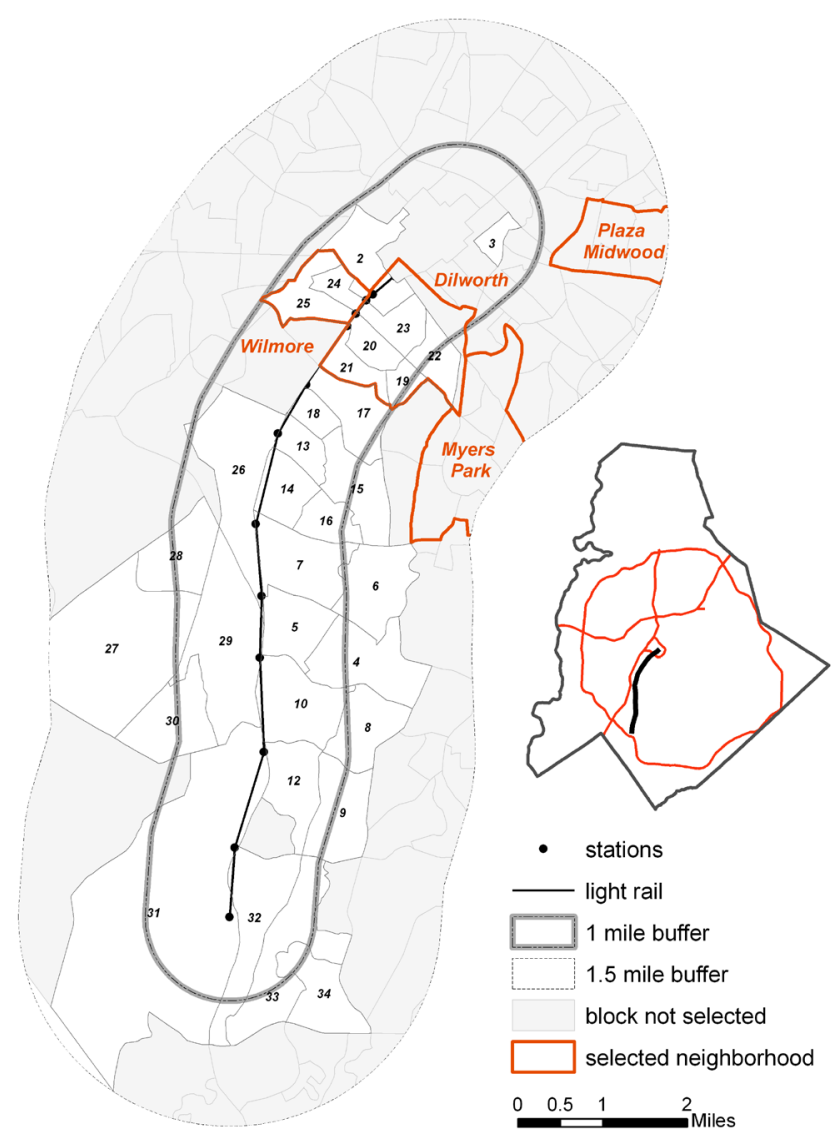

Figure 1: Station map of LYNX in Mecklenburg County and key neighborhoods. Gray shaded block groups were not selected in the analysis due to insufficient single-family house sample.

We consider a period of 11 years, from 1997 to 2008, characterized by a time period before any concrete plans for a light rail system $\left(t_{1}=1997\right.$ to 1998), a planning phase for the light rail ( $\mathrm{t}_{2}=1999$ to 2005), its construction ( $\mathrm{t}_{3}=2005$ to 2007), and is operation ( $t_{4}=2007$ to 2008 - the most current data at the time when this study was conducted), yielding a total of four time periods, allowing for the comparison of housing price fluctuations over a larger time range. We measure the average impact across all of the light rail stations. 


\section{$2.2 \quad$ Data}

\section{Sales price}

We analyze sales prices of single-family houses in the above described study area. For the sake of clarity and parsimony, we have chosen to focus on one property type. The use of singlefamily homes is driven by the fact that they provide a more numerous set of observations and they are simple to analyze, since both the structure and land are owned by one entity. Optimally, one would use land values for this type of analysis, as accessibility is capitalized into land and has no influence on the value of structures. However, data for land values are not generally available. Since rail lines are rarely built in undeveloped areas, there are usually not enough vacant parcels to estimate a model with any degree of statistical significance. In fact, considering all the previous research measuring the influence of rail stations on real estate values, we are aware of only one study that actually uses vacant properties (Knaap, Ding, and Hopkins 2001). Nearly all other relevant studies (including all those cited in the previous section) analyze sales prices for improved parcels and then use statistical techniques to control for the attributes of the associated structures.

The sales price data used in this analysis originate from the Property Ownership Land Records Information System (POLARIS), owned by Mecklenburg County. In addition to sales transactions, POLARIS stores information such as the size of the house, year it was built, number of bedrooms, bathrooms, and fireplaces, and the quality of the building. Before estimating the price model, a few filters were applied to the original dataset:

1. Transactions for which the price was larger than $\$ 1$ million or less than $\$ 5,000$ were excluded, based on the assumption that these extreme values are not consistent with the ordinary market value (Munroe 2007).

2. Home sales that are not ordinary market transaction (e.g., foreclosures) were excluded.

3. Properties beyond a 1609-meter (1-mile) Euclidean distance from the stations were excluded. Most previous studies have demonstrated little impact beyond the immediate vicinity of the station ${ }^{2}$ (Bartholomew and Ewing (in press); Ryan 1999).

In this paper, we adopt a logarithmic model, since it allows

2 Households that live more than one mile from a station can still benefit from the rail system, especially when there is a park-and-ride facility. However, the supply of housing exponentially increases when one considers an area more than a mile away. Further, there are a finite number of parking spaces (numbered in the thousands) for a large supply of housing units that could potentially make use of them. This is not the kind of situation where one would expect land value premiums. the estimated value to vary proportionally with different components of explanatory variables, while the coefficients are interpreted as the percent change in the dependent variable with a one-unit increase (or decrease) in that explanatory variable (Eppli and Tu 1999; Malpezzi 2002; Song and Knapp 2003). Second, it eliminates heteroscedasticity, which is strongly present when using an untransformed sales price variable. To allow for equivalent comparisons across time periods, the sales prices are adjusted to 2005 constant US dollars using the housing price index (HPI) specific to the Charlotte MSA (as provided by Federal Housing Finance Agency).

\section{Independent Variables}

A set of explanatory variables is used to model price fluctuations of single-family houses. Control variables include the age of the house as well as its heated area. The age of the house is squared $\left(\mathrm{age}^{2}\right)$ and added into the housing information, since age of housing may not be linearly correlated with price. Several studies indicate a U-shaped relation between price and housing age (Coulson and McMillen 2008; Coulson and Lahr 2005). Older houses may be more expensive than relatively new houses, while 20- to 40-year-old houses may be characterized by a lower retail value. Heated area is another important variable, which is log-transformed because of its skewed distribution.

The key variable in this analysis is station distance, which is computed as the logarithm of the network distance from a parcel to its nearest transit station. We have chosen to use a continuous distance variable, as opposed to the binary distance band that many of the previously cited studies employ. Specifying binary distance measure requires one to arbitrarily determine the distance from a rail station that no longer influences property values, and we did not feel comfortable with this process. The log transformation of station distance captures the rapidly decreasing influence of a station when moving outside of easy walking distance. Network distance is preferred to Euclidean distance, since the latter may not serve as a real proximity variable. Although some individuals may appear to live close to a transit system, they have to overcome a much greater distance to reach a station. Because the sales transactions used in this analysis occurred at various times across a long study period, it is hard to obtain data for the neighborhood characteristics that are temporally consistent with the time of sale. Census data, which provide a readily available source for neighborhood data, are only collected every 10 years. Thus, instead of specifying neighborhood variables, a set of zonal dummy variables at the census block group level ${ }^{3}$ is used to control for the unique set of socio-demographic and spatial factors associated with a given

3 There is a slight chance that the block group scale may capture too much of the variation in network distance to the nearest station. However, station distance coefficients for the block group model are just as strong as when using geographically larger zones. 
location (e.g., distance to nearby schools, parks, or the CBD). Each parcel is assigned its corresponding neighborhood and block group by means of GIS. Because the properties within any given block group will not have much variation with regard to CBD proximity, the zonal dummy variables implicitly control for proximity to the CBD.

\section{$3 \quad$ Hedonic Price Modeling}

The location of a house - that is, its neighborhood, its distance to the $\mathrm{CBD}$, and its proximity to transportation infrastructure- has a significant impact on its price. Additionally, home prices also reflect property characteristics such as size, age, and quality of any structure on a parcel (Kain and Quigley 1970; Grether and Meiszkowski 1974).

Hedonic Price Analysis (HPA) is a multiple regression model that decomposes housing values into measurable prices and quantities so that value for different dwellings in different places can be predicted and compared (Malpezzi, 2002). To estimate the effect of light rail on housing price, the hedonic regression model uses (1) proximity to rail stations, (2) housing characteristics, and (3) neighborhood fixed effects (i.e., a series of dummy variables representing the neighborhood in which a parcel is located) to predict the sales price of housing units. Holding other variables constant, the change in the price of a house that results from a change in any particular attribute is called the hedonic price or implicit price of an attribute. It assumes that sales price $(\mathrm{y})$ is a function of $D$, which represents the proximity of properties to light rail stations; $H$, housing characteristics; $L$, locational amenities; and $N$, neighborhood characteristics (Hess and Ameida 2007). The conceptual hedonic regression model is:

$$
\hat{y}_{i}=f(D, H, L, N)
$$

Several variables (housing sales price, age of structure, housing heated area, and network distance) are transformed:

$$
\ln \left(\hat{y}_{i}\right)=b_{0}+\sum_{h \in H} b_{h} x_{h}+b_{n} x_{n}+b_{d} \ln \left(x_{d}\right)+\epsilon_{i}
$$

where the dependent variable $\hat{y}_{i}$ is the natural logarithm of the adjusted sales price for each house $i, x_{h}$ is a vector of assetspecific characteristics of the properties, $x_{n}$ is a locational vector (neighborhood dummy variable), $\ln \left(x_{d}\right)$ is a log transformation of network distance to the nearest rail station, and $\epsilon_{i}$ is a normally distributed random error with mean zero. The regression is repeated for each of the four implementation phases, allowing the change in the impact of station proximity to be examined.
4

\section{Results}

\subsection{Hedonic price modeling of housing sale prices}

The spatial pattern of housing values along light rail stations (Figure 2) indicates a higher price value in the southern region of the light rail. To get a complete understanding of the light rail impact on single-family housing values in Charlotte at the four distinct time phases, a hedonic regression model is applied at a block group level. A vector of eight housing characteristics was selected in the model, while careful attention was paid to remove highly correlated variables to reduce multicollinearity ${ }^{4}$. The variables left in the model include age, squared age, height, no fuel, central air conditioning, number of fireplaces, building grade, and Ln (heated area). No fuel and central air conditioning are dummy variables, indicating the presence or absence of any type of heating and air conditioning, respectively. Building grade refers to the quality of the structure (below average to excellent, 1-5). We introduce this variable because the large majority of the homes used in our analysis (5975 out of 6381) were built before 2000 . The explanatory variable height represents the story height.

Table 1: Descriptive statistics for single-family properties ( $\mathrm{n}=6381)$.

\begin{tabular}{ccccc}
\hline & $\min$ & $\max$ & mean & st. deviation \\
\hline sales price & 10000 & 992000 & 197997.82 & 146058.84 \\
age & 1 & 108 & 46.49 & 21.31 \\
heated area $\left(\mathrm{ft}^{2}\right)$ & 480 & 7003 & 1722.25 & 743.16 \\
$\ln$ (heated area) & 6.17 & 8.85 & 7.38 & 0.38 \\
\# fireplaces & 0 & 4 & 0.67 & 0.49 \\
building grade & 0 & 4 & 1.47 & 0.89 \\
\# bedrooms & 1 & 9 & 3.12 & 0.64 \\
$\ln$ (network dist) $(\mathrm{ft})$ & 6.27 & 9.93 & 8.42 & 0.53 \\
\hline Source: POLARIS and Charlotte Area Transit System (CATS)
\end{tabular}

Table 2: Sales statistics for the four time periods under consideration.

\begin{tabular}{ccc}
\hline Time period & Adjusted price (average) & $\mathrm{n}$ \\
\hline$t_{1}$ & 197,950 & 1,592 \\
$t_{2}$ & 206,720 & 2,568 \\
$t_{3}$ & 213,300 & 1,308 \\
$t_{4}$ & 227,840 & 913 \\
\hline
\end{tabular}

4 Pearson's correlation coefficients were run between all the variables, and correlations larger than 0.7 are excluded from the regression. (Munroe 2007). 


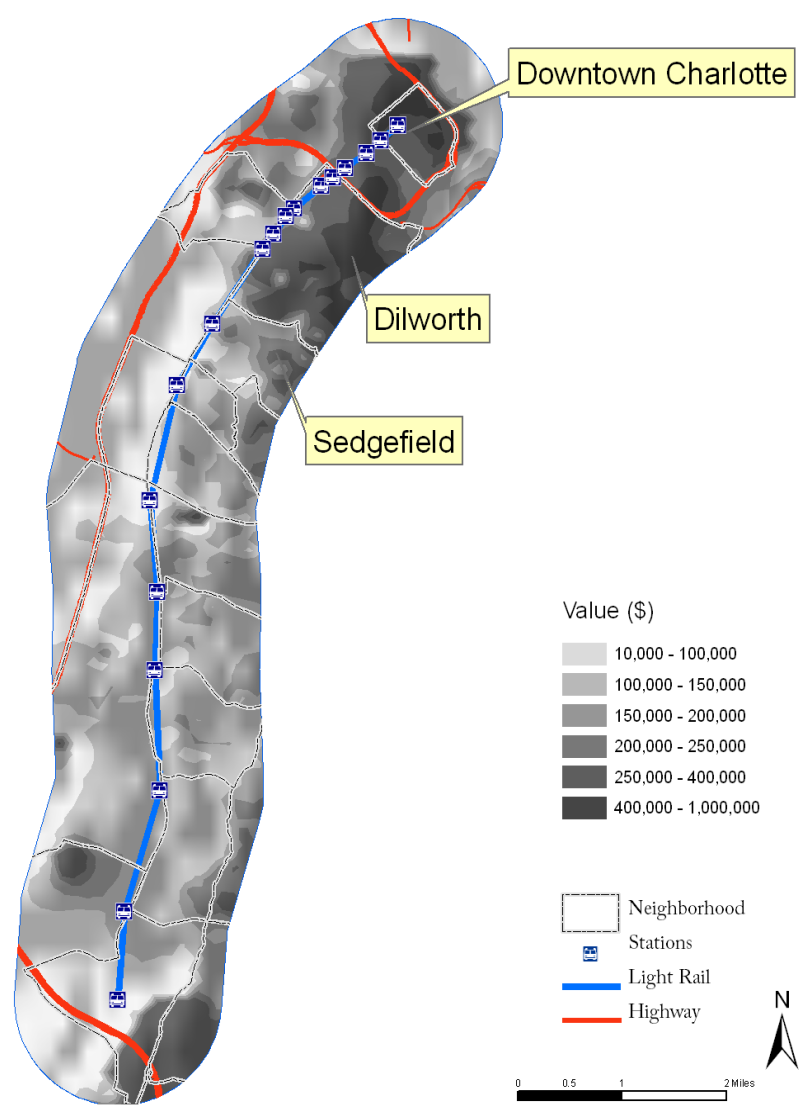

Figure 2: Interpolation of housing price at year 2008.

\section{Hedonic Price Regression Model}

Housing characteristics are combined with block group dummy variables $(n=34)$ to estimate housing sale prices. The $\mathrm{R} 2$ values for the various time periods range from 0.78 to 0.84 . Detailed regression results for each time period in Table 3 indicate that most attributes influencing home values are signifcant at the $\alpha=0.05$ level and have expected positive or negative signs.

From $t_{1}$ to $t_{4}$, signs and coefficients for most variables are stable and consistent with the housing prices. Among housing characteristics, variables such as height, central air conditioning, number of fire places, building grade, and Ln (heated area) are positively correlated with housing price, which is rather intuitive given that larger houses with more fireplaces, better building quality, and a central air-conditioning system will generally experience a higher sale value than houses without these characteristics. With an $L n$ (heated area) coefficient value of 0.337 at time $t_{1}$ for instance, the coefficient is interpreted as a 3.37 percent sales value increase with a heated area larger by 9.29 square meters (100 square feet). On the other hand, houses without fuel will experience a dramatic decrease in price value, since the no fuel variable has a -0.796 coefficient value.
Both age and squared age variables are used to interpret the relationship between housing age with price. The age variable becomes negatively correlated with house price at time period $\mathrm{t}_{4}$ compared with the insignificant relationship shown during the three other time periods of $\mathrm{t}_{2}, \mathrm{t}_{3}$, and $\mathrm{t}_{4}$. Especially at time period $t_{4}$, house prices tend to decrease with age. However, this does not necessarily mean that older houses are not as valuable as newer houses. When looking at the squared age variable, it has a modest yet positive relationship with housing prices, and this relationship increases from $t_{1}$ to $t_{4}$. This suggests that although housing prices went down as house age increased, the relationship is not necessarily linear. The positive coefficient of squared age signals that a U-shape relationship may exist between age and price. In the interest of space, we did not list the 32-block-group dummy variables used in the regression. However, among them, block groups in the Dilworth neighborhood (numbers 19, 20, 21, 22, and 23) exhibit positive coefficients during all four time periods. Known as Charlotte's first "streetcar suburb," the Dilworth neighborhood is ranked high in the Quality of Life index from Mecklenburg County Neighborhood studies.

A test for spatial correlation of the regression residuals in Geoda (Moran 1950; Anselin et al. 2006) reveals low Moran's I values. In fact, Moran's I values are lower when compared with the residuals for the same regression, applied at the Charlotte neighborhood level ${ }^{5}$ (not reported here), implying that block group dummy variables are a suitable scale to capture spatial structure.

\section{Temporal variation of distance to the light rail}

The distance coefficient suggests that proximity to light rail stations contributes modestly to variation in housing value. At all time periods, the coefficient of $L n N e t D$ is is positive but at a decreasing rate, especially at time period $\mathrm{t}_{4}$ (see Table 3 ). At $\mathrm{t}_{1}$, $\mathrm{t}_{2}$, and $\mathrm{t}_{3}$, the positive coefficients indicate that houses tend to have higher values with a greater distance to the nearest station. One plausible explanation is that the Charlotte light rail system occupies what was once a freight rail corridor surrounded by industrial uses. This has had a negative influence on surrounding properties, but this negative influence has dissipated with the introduction of the light rail system. A z-test is conducted to evaluate whether coefficients at each time period are comparable (Clogg 1995; Paternoster et al. 2006). The value of $\mathrm{z}$ indicates whether the two coefficients are significantly different from one another. Specifically, if $\mathrm{z}>=1.96$ or $\mathrm{z}<=-1.96$, the test is significant at the $\alpha=0.05$ level. From Table 4, the $\operatorname{Ln}$ (network distance) coefficient is significantly smaller in $\mathrm{t}_{4}$ than the other

5 The City of Charlotte has its own neighborhood designations. These neighborhoods are generally much larger than block groups. 
Table 3: Regression coefficients for the four time periods, block group level.

\begin{tabular}{ccccc}
\hline & T1 & T2 & T3 & T4 \\
\cline { 2 - 5 } Variable & Coefficient & Coefficient & Coefficient & Coefficient \\
\hline (constant) & $8.196^{*}$ & $7.406^{*}$ & $8.123^{*}$ & $8.249^{*}$ \\
\hline age & Property characteristics & & & \\
\hline squared age & $-0.004^{*}$ & -0.001 & -0.003 & $-0.006^{*}$ \\
height & $4.37 \mathrm{E}-05^{*}$ & $2.59 \mathrm{E}-05$ & $4.16 \mathrm{E}-05^{*}$ & $8.21 \mathrm{E}-05^{*}$ \\
no fuel & $0.125^{*}$ & $0.062^{*}$ & $0.076^{*}$ & 0.053 \\
central air conditioning & $-0.796^{*}$ & 0.302 & 0.032 & $-0.794^{*}$ \\
building grade & $0.045^{*}$ & $0.080^{*}$ & $0.090^{*}$ & $0.101^{*}$ \\
\# freplaces & $0.034^{*}$ & $0.027^{*}$ & $0.032^{*}$ & $0.059^{*}$ \\
In (heated area) & $0.089^{*}$ & $0.064^{*}$ & $0.057^{*}$ & 0.004 \\
& $0.337^{*}$ & $0.392^{*}$ & $0.338^{*}$ & $0.455^{*}$ \\
\hline In (network distance) & Rail Impact & & & \\
(std. error) & $0.123(.028)^{*}$ & $0.169(.022)^{*}$ & $0.148(.027)^{*}$ & $0.052(.033)$ \\
$R^{2}$ & $0.779^{*}$ & $0.786^{*}$ & $0.811^{*}$ & $0.837^{*}$ \\
Morans I (residuals) & $0.097^{*}$ & $0.110^{*}$ & $0.167^{*}$ & $0.021^{*}$ \\
\hline
\end{tabular}

*Note: significant at $\mathrm{p}<0.05$

time periods, which confirms the hypothesis that proximity to a light rail station at time period $\mathrm{t}_{4}$ contributes positively to house prices relative to earlier time periods. As $\mathrm{t}_{2}$ and $\mathrm{t}_{3}$ are not significantly different from $t_{1}$, it appears that the rail investment did not affect Charlotte single-family home prices until the rail system actually began operation. This stands in contrast to other studies that have illustrated price increases during the planning stages of a rail system (Damm et al. 1980; McMillen and McDonald 2004). Possible reasons may be attributed to (1) the planning phase of the light rail with only part of the system being implemented, (2) significantly less-congested traffic in Charlotte compared to Boston or Chicago, which reduces the attraction of living closer to light rail, and hence, (3) the limited awareness of public transportation.

Table 4: $\mathrm{Z}$ test for coefficients comparison among models

\begin{tabular}{ccccccc}
\hline & $\mathbf{t}_{1-2}$ & $\mathbf{t}_{1-3}$ & $\mathbf{t}_{1-4}$ & $\mathbf{t}_{2-3}$ & $\mathbf{t}_{2-4}$ & $\mathbf{t}_{3-4}$ \\
\hline $\begin{array}{c}\text { Z-test } \\
\text { (blockgroup) }\end{array}$ & -1.29 & -0.64 & 1.64 & 0.60 & 2.95 & 2.25 \\
\hline
\end{tabular}

\section{Sensitivity Analysis}

Using the coefficients of each variable from our hedonic model, a sample of adjusted price is computed holding other variables constant while changing the value of the network distance. We consider two similar 139.35-square-meter (1500-square-foot) houses in excellent condition (building grade $=5$ ), 20 years old with air conditioning, one fireplace each and regular fuel, but with one located 402 meters ( $1 / 4$ mile) from the nearest station and the other 1609 meters ( 1 mile). Figure 3 indicates that, for each time period, as the network distance to the light rail increases, so do housing prices. However, the difference in price for two houses becomes marginal in time $t_{4}$, indicating that it is becoming more desirable to live closer to the light rail. This empirically shows that the light rail may be offsetting the negative influence that previously existed in this corridor.

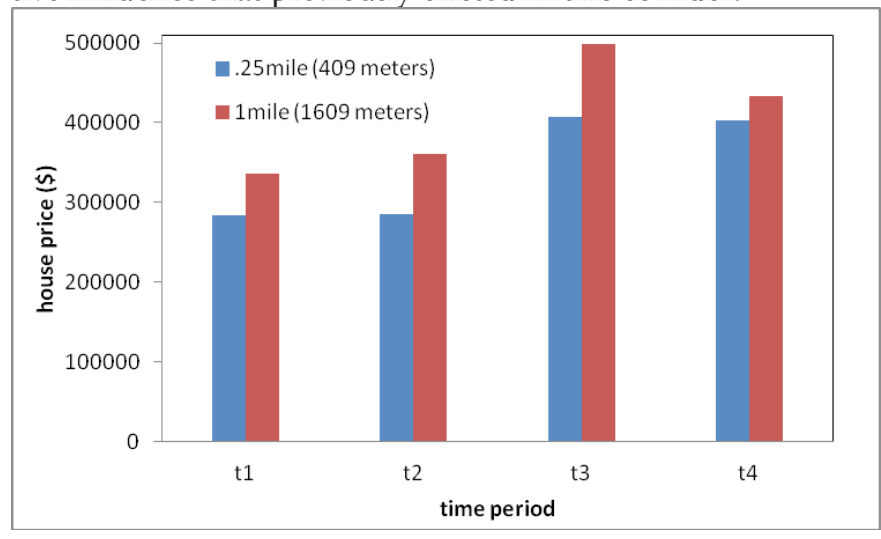

Figure 3: Variation in adjusted house price $(\$)$ at all four time periods at a distance of 402 meters ( 0.25 mile) and 1609 meters (1 mile).

\section{Conclusion}

In this paper, we apply a hedonic regression model (hedonic 
price analysis) at a block group scale to evaluate the impact of a newly added light rail system on single-family housing values in Charlotte, North Carolina. Most research efforts have been cross-sectional, and this study takes a longitudinal approach by repeating the same hedonic regression analysis at four different time periods, coinciding with the pre-planning, planning, construction, and operation phase of the light rail system.

Results from this study reveal that before the rail system began operation, proximity to the future rail corridor had a negative influence on home prices. This is likely due to the presence of industrial land use zones around existing stations. However, when compared across the four time periods, housing prices have started to react positively to light rail investment during the operational phase. This may suggest that accessibility to reliable transportation has improved the attractiveness of single-family houses in the vicinity of light rail stations, or that some of the unattractive industrial uses have disappeared, or that light rail investment has improved the image of the area. Locally, it is possible that after the light rail system went into operation, the accessibility provided by newly built light rail stations improved the attractiveness of these areas. Another explanation is that, due to the concept of transit-oriented development of the Charlotte land planning commission, it is likely that multiple-family houses or commercial properties have started to concentrate in the vicinity of light rail stations.

In this paper, we have used a distance of 1609 meters (1 mile) around light rail stations to extract those single-family houses for which sale prices would potentially be influenced by the proximity to transit. O'Sullivan and Morrall (1996) indicate that individuals living in suburban neighborhoods are willing to overcome a greater distance to get to a transit station than those individuals living in denser, urban areas. As future research, the distance buffer can be modified to be stationspecific, better reflecting the type and complexity of neighborhoods surrounding them.

In this study, we were limited in our ability to fully measure the effect on home values of the railway operating over a number of years, after it had matured. As a future study, we would like to extend our analysis over a wider period of time after the rail entered its operational phase. Spatially explicit regression methods exist to test whether the price premium associated with rail proximity will fluctuate from station to station, especially with varying distance from the CBD.

\section{References}

Agostini, C. and G. Palmucci. 2008. The anticipated capitalization effect of a new metro line on housing prices. Fiscal
Studies, 29: 233-256.

Alonso, W. 1964. Location and land use: Toward a general theory of land rent. Cambridge, MA: Harvard University Press.

Anselin, L., I. Syabri, and Y. Kho. 2006. GeoDa: An introduction to spatial data analysis. Geographical Analysis, 38: 5-22.

Baldassare, M., R. Knight, and S. Swan. 1979. Urban service and environmental stressor: The impact of the Bay Area Rapid Transit System on residential mobility. Environment and Behavior, 11: 435-450.

Bartholomew, K.E. and R. Ewing. In Press. Hedonic price effects of pedestrian and transit-oriented development. Journal of Planning Literature.

Benjamin, J. D. and G. S. Sirmins. 1996. Mass transportation, apartment rent and property values. Journal of Real Estate Research, 12: 1-8.

Bowes, D. and K. R. Ihlanfeldt. 2001. Identifying the impacts of rail transit stations on residential property values. Journal of Urban Economics, 50: 1-25.

Cervero, R. and M. Duncan. 2002. Benefits of proximity to rail on housing markets: Experiences in Santa Clara County. Journal of Public Transportation, 5: 1-18.

Clogg, C.C., E. Petkova, and A. Haritou.1995. Statistical methods for comparing regression coefficients between models. American Journal of Sociology 100: 1261-1293.

Coulson, N.E. and D.P. McMillen. 2008. Estimating time, age and vintage effects in housing prices. Journal of Housing Economics, 17: 138-151.

Coulson, N.E. and M. Lahr. 2005. Gracing the land of Elvis and Beale Street: Historic designation and property values in Memphis. Real Estate Economics, 33: 487-507.

Damm, D., S.R. Lerman, E. Lerner-Lam, and J. Young. 1980. Response of urban real estate values in anticipation of the Washington metro. Journal of Transport Economics and Policy, 14(3): 315-336.

Davis, F.W. 1970. Proximity to a rapid rail transit station as a factor in residential property values. The Appraisal Journal, 38: 554-572.

Debrezion, G., E. Pels, and P. Rietveld. 2007. The impact of railway stations on residential and commercial property value: A meta-analysis. The Journal of Real Estate Finance and Economics, 35: 161-180

Diao, Mi. 2007. A proposal of measuring the impact of urban form on property values - A hedonic price analysis. Department of Urban Studies and Planning. Massachusetts Institute of Technology.

Dunbaugh, E. 2008. Designing communities to enhance the safety and mobility of older adults: A universal approach. Journal of Planning Literature. 23: 17-36. 
Dunphy, R. T. and the Department of Community and Economic Resources. 1982. Trends before Metrorail: a Metrorail before-and-after study report. Metropolitan Washington Council of Governments, Washington, DC.

Eppli, M.J. and C.C. Tu .1999. Valuing the new urbanism: The impact of the new urbanism on prices of single-family homes. Washington, DC: ULI — the Urban Land Institute.

Gatzlaff, D. H. and M. Smith.1993. The impact of the Miami Metrorail on the value of residences near station locations. Land Economics, 69(1): 54-66.

Gibbons, S. and S. Machin. 2005. Valuing rail access using transport innovations. Journal of Urban Economics, 57: 148-169

Grass, R. G. 1992. The estimation of residential property values around transit station sites in Washington, DC. Journal of Economics and Finance, 16: 139-146.

Grether, D. and P. Mieszkowski. 1974. Determinants of real estate values. Journal of Urban Economics, 1: 127-145.

Hess, D.N. and T.M. Almeida. 2007. Impact of proximity to light rail rapid transit on station-area property values in Buffalo, New York. Urban Studies, 44: 1041-1068.

Huang, H. 1996. The land-use impacts of urban rail transit systems. Journal of Planning Literature, 11(1): 17-30. doi: 10.1177/088541229601100103.

Federal Housing Finance Agency. 2009. Housing price index-Charlotte MSA HPI data. Retrieved from http:// www.fhfa.gov/Default.aspx?Page=87. Last accessed: September 14, 2010.

Kain, J.F. and J.M. Quigley. 1970. Evaluating the quality of the residential environment. Environment and Planning, 2: 23-32.

Knaap, G., C. Ding, and L. Hopkins. 2001. Do plans matter? The effects of light rail plans on land values in station areas. Journal of Planning Education and Research, 21(1): 32-39.

Knight, R. and L. Trygg. 1977. Evidence of land use impacts of rapid transit systems. Transportation, 6: 231-247.

Lee, D.B., 1973. Case studies and impacts of BART on prices of single family residences. Berkeley, CA: University of California, Institute of Urban and Regional Development.

Lewis-Workman, S. and D. Brod. 1997. Measuring the neighborhood benefits of rail transit accessibility. Transportation Research Record, 1576: 147-153.

Malpezzi, S. 2002. Hedonic pricing models and house price indexes: A select review. In Housing Economics and Public Policy: Essays in Honour of Duncan Maclennan, edited by Kenneth Gibb and Anthony O'Sullivan. Oxford: Blackwell Publishing.

McMillen, D. and J. McDonald. 2004. Reaction of house prices to a new rapid transit line: Chicago's Midway line,
1983-1999. Real Estate Economics, 32(3): 463-486.

McDonald, J. F. and C.I. Osuji. 1995. The effect of anticipated transportation improvement on residential land values. Regional Science and Urban Economics, 25(3): 261-278.

Moran, P.A.P. 1950. Notes on continuous phenomena. Biometrika, 37:17-23.

Muller, P.O. 1995. Transportation and urban form: Stages in the spatial evolution of the American metropolis. In The Geography of Urban Transportation (2nd ed.), edited by Susan Hanson. New York, London: The Guiford Press.

Munroe, D.K. Exploring the determinants of spatial pattern in residential land markets: Amenities and disamenities in Charlotte, NC, USA. Environment and Planning B 34: 336-354.

Ong, P. M. and D. Houston. 2002. Transit, employment and women on welfare. Urban

Geography, 23: 344-364.

O'Sullivan, S. and J. Morrall. 1996. Walking distances to and from light-rail transit stations. Transportation Research Record, 1538: 19-26.

Paternoster, R., R. Brame, P. Mazerolle, and A. Piquero. 2006. Using the correct statistical test for the equality of regression coefficients. Criminology, 36: 859-866.

Rapid Transit Planning. 2010. Charlotte Area Transit System. Retrieved from http://charmeck.org/city/charlotte/cats/ planning/Pages/default.aspx. Last accessed: September 17, 2010.

Richardson, B. 1999. Toward a policy on a sustainable transportation system. Transportation Research Record, 1670: 27-34.

Rosen, S. 1974. Hedonic prices and implicit markets: product differentiation in pure markets. Journal of Political Economics, 82: 34-55.

Ryan, S. 1999. Property values and transportation facilities: Finding the transportation-land use connection. Journal of Planning Literature, 13: 412-427.

Song and Knaap. 2003. New urbanism and housing values: a disaggregated assessment. Journal of Urban Economics, 54: 218-238.

Voith, R. 1993. Changing capitalization of CBD-oriented transportation systems: Evidence from Philadelphia, 19701988. Journal of Urban Economics, 33: 361-376.

Weinstein, P.B. and P.T. Clower. 2002. An assessment of the DART LRT on taxable property valuations and transit oriented development. Dallas: University of North Texas, Center for Economic Development and Research. 